\title{
A SIMPLIFIED AGGREGATE APPROACH TO DESIGN EFFECTIVE ESCAPE ROUTES FOR BUILDINGS
}

\author{
M. DI GANGI \\ Department of Civil and Environmental Engineering, Informatics and Applied Mathematics, University of Messina, Italy.
}

\section{ABSTRACT}

In this paper, a specific methodology to define effective escape routes using evacuation time as selection criterion is shown. Feasible solutions are generated and compared in terms of evacuation time computed by means of an aggregate model. The proposed aggregate approach can be easily implemented and allows a prompt first attempt evaluation in case of the lack of commercial software or tools suitable to perform advanced and more sophisticated simulations. Results obtained from simulations are compared with data recorded from an experimentation on a test site conducted in a primary school located in an Italian town; an application of the whole procedure, consisting in designing escape routes for an existing school, is also presented.

Keywords: evacuation, simulation.

\section{INTRODUCTION}

One of the aspects that in the last years attracted the attention of some experts of the field on transport model consists in the analysis of working modality of a transport system when it is subjected to emergency conditions. That means to analyze how to reformulate some approaches commonly used in ordinary conditions in order to take into account the particular operative conditions due to the emergency status of the transport system. Such an approach should allow the availability of tools to conduct simulations of evacuations avoiding expensive drills or to give useful indications to enhance evacuation processes of different extended areas (building, industrial site, town, etc.). Traditionally, risk is defined as the product of three factors: probability, vulnerability and exposure (of a population, goods, etc.) [1]. To reduce risk, attention has been usually turned to two main components as the probability that the event occurs (whenever possible, that is essentially for anthropic events) and the vulnerability related to resistance of infrastructures.

To dishearten risk, it is also possible to operate on exposure component if, since the occurring of the event to the propagation of the effects to population, it is possible to evacuate the whole (or a part of the) population. Effects produced in the space connected to disaster event can be: punctual [2]; of area or diffused [3]. These effects change on time with temporal evolution of event. For same kind of disasters (i.e. tsunami, presence of a bomb, etc.), during time interval it is possible to intervene to reduce risk. On the contrary, for other kind of events (i.e. earthquakes), the duration of this time interval is very short. Within this work, only events with delayed effects have been taken into consideration. In this paper, we focus on punctual delayed effects on time [3].

An evacuation can be defined as a general mobilization of people (and/or goods) due to the occurrence of a calamitous event. Its main objective is to reduce the number of people (and/or goods) present in the area where the event strikes [4]. Evacuation drills are mainly performed to practice the people to leave the interested area; these tests can also be used for getting information concerning the behavior of the people in order to build a set of mathematical models able to reproduce the evacuation. These models can constitute a Decision Support System (DSS) to be used for planning emergences [5].

Simulation models, used to perform quantitative analysis on the operational conditions of a transportation system in emergency circumstances, differ depending on the hypotheses made on the representation of flow characteristics. Among proposed classifications and reviews, those proposed by Gwynne et al. [6], Fire Model Survey [7], Kuligowski and Peacock [8] and Olenick and Carpenter

(C) 2014 WIT Press, www.witpress.com

ISSN: 1743-7601 (paper format), ISSN: 1743-761X (online), http://journals.witpress.com DOI: $10.2495 /$ SDP-V10-N5-734-754 
[9] can be considered in order to specify a common terminology, structure and data gathering in order to approach a classification of the models.

Pedestrian evacuation has been considered in the last years a lead issue from both theoretical and practical point of view. On the one hand, the details of pedestrian evacuation have been cast into mathematical formulations yielding to various representations of pedestrian interactions [10-24]. On the other hand, theoretical developments have conducted to model emergency evacuation and situations [25-45] using sophisticated simulation methodologies.

Computational complexity of proposed models require, to analyze outflow conditions of networks, the adoption of dedicated and sophisticated tools. On the other hand, there is also, in certain circumstances, a need for simple tools able to quantify, in terms of evacuation time, the effectiveness of an evacuation plan. Such aggregate approaches, in order to simulate pedestrian movements, consider laws of motion of pedestrian flow using, in general, relationships between speed and density [46-49] or deriving from continuum theory of traffic flows [50,51].

In this paper, a specific methodology (models and procedure) to select effective escape routes using evacuation time as selection criterion is shown. To simulate evacuation (and compute evacuation time), an aggregate approach that allows a prompt first attempt evaluation in case of the lack of commercial software or tools suitable to perform advanced and more sophisticated simulations is proposed. This article is structured as follows: in Section 2, the proposed method is described to define evacuation routes in case of buildings where a validation of proposed model to compute evacuation time comparing results obtained from simulation with recorded data from on site experimentation is also reported. In Section 3, an application to a real case represented by a provisional school unit built after l'Aquila earthquake is presented and some remarks are reported in Section 4.

\section{PROPOSED APPROACH}

The proposed approach can be summarized in the following steps, whose connections are sketched in Fig. 1.

1. Zoning of the building: Every starting and terminal area of the building is approximated with single points (zone centroids) representing origin or destination nodes of escape routes.

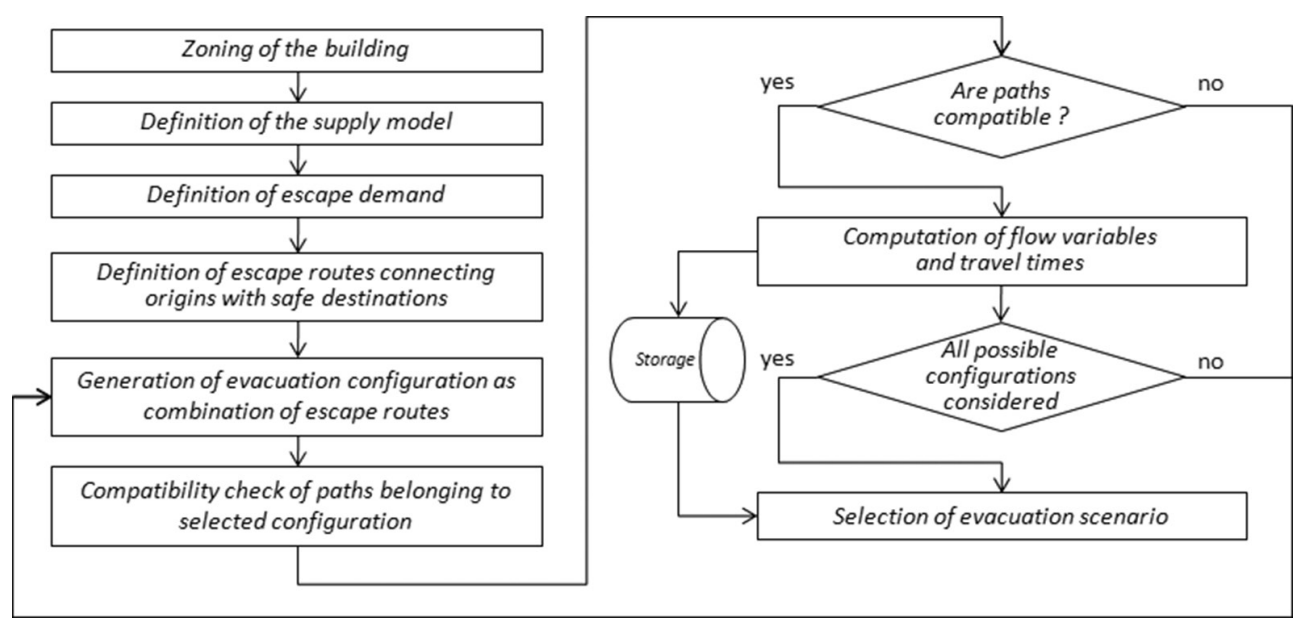

Figure 1: Scheme of the connections among activities of the proposed methodology. 
2. Definition of the supply model of the building: The building is schematized considering the network of all possible pathways considering the elements (corridors, stairs, etc.) they are composed by; such a network is represented by means of fundamentals of graph theory.

3. Definition of escape demand: Starting from data concerning occupants (number and positions), the number of people staying in each area is attributed to the correspondent origin node representing the considered site.

4. Definition of escape route: In this step, evacuation routes are defined for each area representing the origin of evacuation and considering as destination nodes the whole set of available assembly point. Considering the graph of the network representing the elements of the building, in terms of components of the escape ways (ramps, corridors, stairs, etc.), a set of path connecting each origin with each possible safe destination is generated. To explore a wide range of alternatives, for each origin-destination pair more than one evacuation route is taken into consideration. Paths are described as a sequence of elements of the graph obtained from the supply model, as defined above.

5. Generation of evacuation configuration: Starting from the computed set of evacuation routes, feasible evacuation scenarios are built taking account of some selection rules introduced in order to avoid unnatural behaviors.

6. Computation of flow variables and travel times: For the considered scenario, using an aggregate model, travel times and flow characteristics are computed in order to define some indicators on evacuation conditions such as total travel time and evacuation time.

7. Selection of evacuation scenario: The effective scenario is selected considering, among all the simulated configurations, the one that minimize evacuation time and/or total travel time.

The descriptions concerning operations conducted and models considered at each step of the procedure are given in the following.

\subsection{Zoning of the building}

Every starting and terminal area is identified within the building (and eventually its surroundings if safe areas are located outside the building) yielding to the definition of origin and destination zones. Every zone is approximated with a single point (zone centroid) representing origin or destination nodes of escape routes that can be divided in:

- Zone centroids: These nodes represent the barycenter of each zone (rooms, offices, etc.) comprising the building. They sum up the origins of the trips of all the people who, at emergency time, are within the considered area making up a zone. There is a centroid for each zone in which the building is divided.

- Destination nodes (centroids): These represent the safe areas towards which people converge in an emergency; they correspond to the destinations of evacuation routes.

2.2 Definition of the supply model

In this step, geometric characteristics of elements of the building are acquired; then, considering the elements of a building, the classes of components making up the graphs are:

- Network nodes: These are located at each potential change of direction along a generic evacuation route or at significant variations in geometric and/or functional characteristics of a trunk (i.e. width variations). 
- Real arcs: These represent the connection between two network nodes or a network and a destination node; they coincide with trunks of the pedestrian network and are classified into flat ramps (corridors) and descending or ascending ramps (stairs).

- Connector arcs: These are used to represent the connection between an area centroid and a network node.

\subsection{Definition of escape demand}

In this step, data concerning occupants, defining both their number and their positions, are acquired. Those values are attributed to the correspondent origin nodes representing each considered site (zone centroid). Different scenarios should be considered for the analysis of evacuation considering different numbers and distributions of occupants.

\subsection{Generation of escape routes - path generation}

After building the graph of the network representing the elements, in terms of components of the escape ways (ramps, corridors, stairs, etc.) of the building, a set of evacuation routes connecting each origin with each defined safe destination is generated. To explore a wide range of alternatives, for each origin-destination pair more than one path is taken into consideration. To define these evacuation routes, a set of paths is generated considering a $\mathrm{K}$ shortest loopless path algorithm considering as arc cost its travel time. An analysis of such algorithms is beyond the bounds of this paper; anyway one of the most used algorithm is the one proposed by Yen [52]; interested readers can find the necessary insights on the matter in Gallo and Pallottino [53] and a review of bibliography can be found in a web page edited by Eppstein [54].

One of the possibilities, in order to take into account the environmental condition of each link within conventional path search algorithms, can be to weight travel time associated with the generic arc of the graph by means of the level of risk associated with the arc [55], assuming that the role of risk can be associated similarly to the one played by saturation level in congested networks. The relationship between the weighted arc cost and the travel time can be written as follows:

$$
T w_{i}=T t_{i}\left\{1+\alpha\left[\ln \left(1 / s_{i}\right)\right]^{\beta}\right\}
$$

where $T w_{i}$ is the weighted cost associated with arc $i$; $T t_{i}$ is the travel time of arc $i ; s_{i}$ is a safety probability $0<s_{i} \leq 1$; and $\alpha, \beta$ are parameters.

The level of the reliability of an arc (safety probability) depends on the nature of the considered event (i.e. an evacuation route using downstairs can be considered safe in case of fire but can be unsafe in case of flood).

\subsection{Generation of feasible alternatives}

The number of alternatives is strictly influenced by the value assumed the number $K$ of alternative evacuation routes considered for each origin/destination pair, since the number of potential alternatives is given by the permutation of the $K$ paths on $N_{\text {od }}$ origin/destination pairs, that is $N_{\text {od }}{ }^{\mathrm{K}}$ (in the hypothesis that for every pair, it is possible to identify $k$ different paths; in general if $K_{i}$ is the number of paths for the $i$ th pair, the number of potential alternatives is given by $\Pi_{i \in o d} K_{i}$ ).

Scenario is generated by applying a selection rule to the set of potential alternatives. The rule here introduced, in order to define a feasible set, consists in eliminating those combinations where contra 
flow is potentially allowed; this implies that each element of the network (ramp, corridor, stair, etc.) can be covered by evacuating people in one way only.

To establish feasibility, given a path $k$ let $l_{k}(r, s)$ be a generic arc belonging to path $k$ connecting nodes $r$ and $s$; two paths, $h$ and $k$, are compatible if, considering each $\operatorname{arc} l_{h}(r, s)$ of path $h$, it does not exist an arc $l_{k}(s, r)$ belonging to path $k$. Such a rule is implemented by defining a compatibility incidence matrix $\boldsymbol{C}\left[n_{k} \times n_{k}\right]$, where the generic element $c_{h k}$ is equal to 1 if paths $h$ and $k$ are compatible, otherwise it is equal to 0 . A feasible scenario is thus made up by a set $\Sigma$ of routes compatible to each other, that is $c_{h k}=1 \forall h, k \in \Sigma$.

\subsection{Computing flow variables and evacuation time}

The proposal of this method arises from the need to have a tool, even though approximate, able to give some indications both on the outflow conditions and on the evacuation times of a building. One of the advantages of this method consists of the possibility to evaluate evacuation times with the only support of a common worksheet application, avoiding the necessity to use specific commercial software.

The proposed method of estimating evacuation time is based on the following assumptions:

- All occupants will begin evacuation at the same time and will not hinder each other.

- Occupants will evacuate via a previously defined escape route.

- Initial walking speed depends on the density of persons, assuming that the flow is only in the direction of the escape route, and that there is no overtaking.

- Full availability of escape arrangements is considered, unless otherwise stated.

- People can move unhindered.

- Effects of passenger age and mobility impairment, flexibility of arrangements, unavailability of corridors and restricted visibility due to smoke can be accounted for in specific correction factors.

Proposed method can be summarized through a succession of operations finalized to the evaluation of evacuation time. Such operations are listed in the following and depicted in the diagram shown in Fig. 2. With regard to the adopted cost function, for connector arcs a constant speed function was considered; for corridors and descending flights, the considered relationships are more in depth analyzed in [2] and summarized in Table 1.

2.6.1 Demand-supply interaction model

- Computation of occupants for each element $q_{i}$. For each element of escape routes, the flow of occupants (vector $\boldsymbol{q}$ ) is computed using the arc-path incidence matrix (A) as $\boldsymbol{q}=\boldsymbol{A d}$, where $\boldsymbol{d}$ is the vector of demand.

- Computation of the specific flow $\left(q_{s}\right)$. This value is computed by dividing flow $q$ by the effective width $w$ of the considered element except for connectors; for those latter components, specific relationships based on density are adopted.

- Computation of speed. Once specific flow $q_{s}$ is known, the following two cases arise:

- Values of $q_{s}$ do not reach the value $q_{s}^{\max }$ of characteristic maximum specific flow for the considered element; speed $v^{\prime}$ is computed by using specific relationships depending on specific flow.

- Values of $q_{s}$ overtake the value $q_{s}{ }^{\max }$ of characteristic maximum specific flow for the considered element; in this case, queues arise in correspondence to transition points; correspondent speed $v^{\prime \prime}$ is given by the limit value indicated by relationships expressing speeds depending on specific flow. 

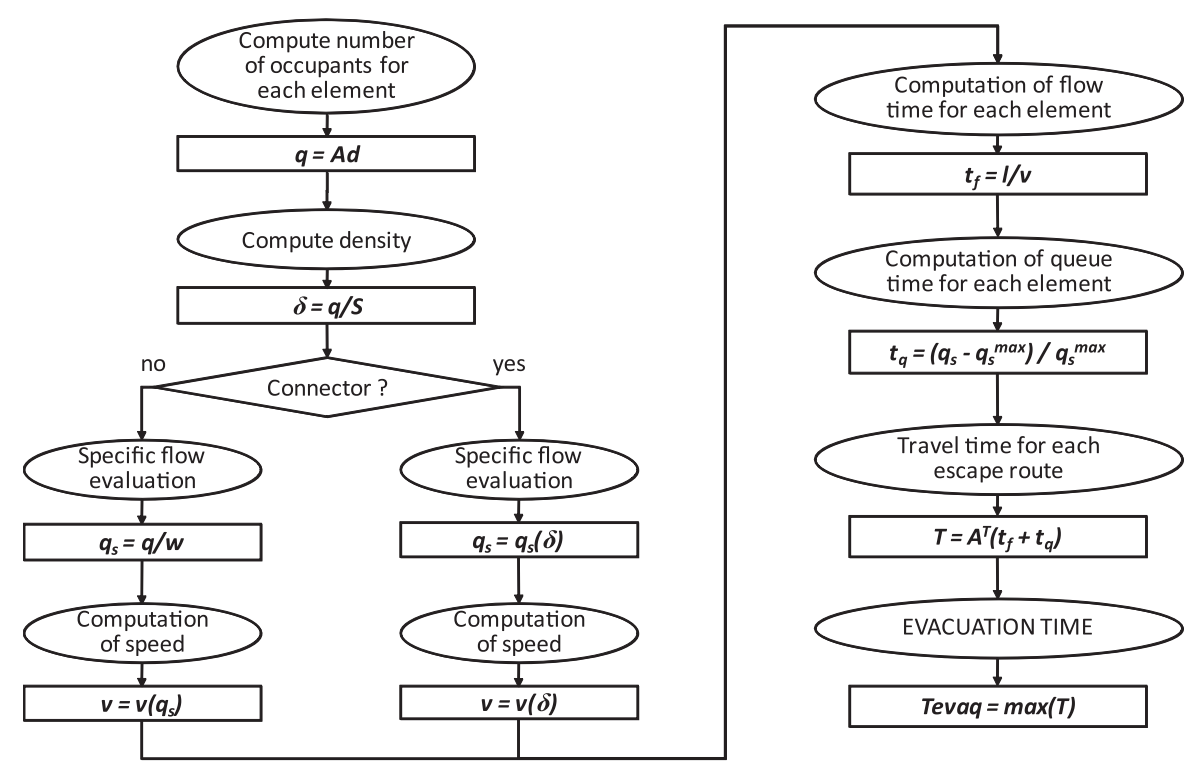

Figure 2: Scheme of the operations performed to compute evacuation time.

Table 1: Cost functions adopted for the simulation.

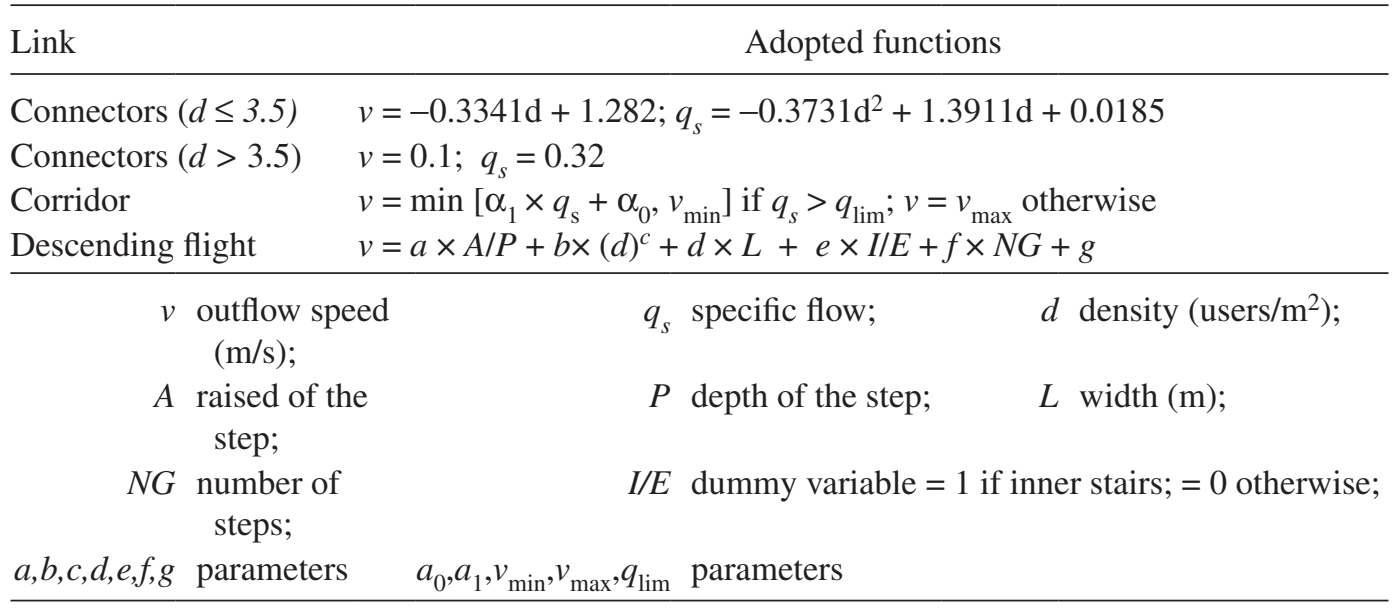

\subsubsection{Computation of times}

- Computation of flow time for each element $\left(t f_{i}\right)$. Those values are computed as $t f_{i}=l_{i} / v_{i}$ once the walking speed for each considered element was evaluated.

- Computation of queue time for each element $\left(t q_{i}\right)$. Those values are computed as $t q_{i}=$ $\left(q_{s}-q_{s}^{\max }\right) / q_{s}{ }^{\max }$ depending on specific flow $q_{s}$ and the value $q_{s}$ max of characteristic maximum specific flow for the considered element. 
- Computation of travel time for each escape route $(T)$. Travel times are computed as $\boldsymbol{T}=$ $\boldsymbol{A}^{T}\left(\boldsymbol{t}_{\boldsymbol{f}}+\boldsymbol{t}_{\boldsymbol{q}}\right)$, for the whole set of evacuation routes, considering the arc-path incidence matrix.

- Computation of evacuation time. After computing travel time for each evacuation route, the higher value $T$ among all the travel times is considered as the evacuation time.

\section{APPLICATIVE CONTEXT}

\subsection{Model calibration}

The part of the methodology concerning demand/supply interaction has been calibrated in a real context [56], where evacuation drills have been carried out in order to collect data to validate proposed models.

As an example, considering the proposed relationship for descending flight in Table 1, parameters were calibrated using the least-squares method, that is minimizing the sum of square differences between observed values and values provided by the model considered whose parameters have to be known. Referring to the above-cited model, the expression is

$$
(a, b, c, d, e, f, g)=\underset{a, b, c, d, e, f, g}{\arg \min } \Sigma_{i=1, \ldots, N}\left(t_{i, o b s}-t_{i, m o d}\right)^{2}
$$

where $N$ is the number of observations; $t_{i, o b s}$ is the observed value of the time needed for the $i$ th user to go down the stairs; and $t_{i, m o d}$ is the value estimated by the model of the time needed for the $i$ th user to go down the stairs.

Calibration was conducted on a randomly drawn sample of $50 \%$ of observations. Subsequently, the calibrated models were validated through an informal test on the calibrated parameter sign and RMSE\% statistic:

$$
\operatorname{RMSE} \%=100\left(\left(\sum_{i=N}\left(t_{i, o b s}-t_{i, m o d}\right)^{2}\right) / N\right)^{1 / 2} /\left(\Sigma_{i=N} t_{i, o b s} / N\right)
$$

Calibration results are shown in Table 2.

In the case of lack of experimental data to be used for the specification and calibration of the cost functions, formulations introduced in literature can be used. As an example, relationships obtained from some experimental results and observations by Kholshevnikov et al. [49] are provided in Table 3.

\subsubsection{The test site}

The methodology is applied to verify the school evacuation plan in a town (Melito Porto Salvo) of south Italy. The scenario simulated concerns an incident involving a tank transporting hazardous goods which, on a workday morning (8.00 am to 12.00), is supposed to leak. Since the presence of a potentially disastrous event is announced, the mayor decides that the surrounding area that contain the school building must be evacuated. The school evacuation plan stipulates that everybody must gather at a site in front of the building (called first assembly point); according to the town evacuation plan, the school's staff and pupils will be led to the refuge area located about $2 \mathrm{~km}$ from the school by means of a bus service starting from another gathering place (second assembly point) as shown in Fig. 3.

\subsubsection{Monitoring}

Two evacuation tests (drills) are carried out: in the first test, the town hall and school buildings are involved; in the second test, besides public buildings, private and commercial buildings in the area 
Table 2: Calibrated parameters for the adopted cost functions.

\begin{tabular}{|c|c|c|c|c|c|c|}
\hline \multicolumn{7}{|c|}{ Descending flight } \\
\hline$a$ & $b$ & $c$ & $d$ & $e$ & $f$ & $G$ \\
\hline-0.845 & -0.029 & 2.000 & 0.905 & 0.299 & -0.082 & 0.357 \\
\hline \multicolumn{7}{|c|}{ Corridors } \\
\hline & $\begin{array}{l}q_{\lim } \\
0.65\end{array}$ & $\begin{array}{l}v_{\min } \\
0.67\end{array}$ & $\begin{array}{l}v_{\max } \\
1.20\end{array}$ & $\begin{array}{c}\alpha_{1} \\
-0.8154\end{array}$ & $\begin{array}{c}\alpha_{0} \\
1.7302\end{array}$ & \\
\hline
\end{tabular}

Table 3: Experimental cost functions (Source: Kholshevnikov et al. [49]).

$v=\min \left\{v_{0} \times\left[1-a_{j} \log \left(d / D_{j}\right)\right], v_{0}\right\}$ if $d>0 ; v=v_{0}$ otherwise $d$ density (users $/ \mathrm{m}^{2}$ )

\begin{tabular}{lccc}
\hline & $v_{0}$ & $a_{j}$ & $D_{j}$ \\
\hline Horizontal outdoors & 1.20 & 0.407 & 0.69 \\
Horizontal indoors & 1.20 & 0.295 & 0.51 \\
Door aperture & 1.20 & 0.295 & 0.65 \\
Stair downwards & 1.00 & 0.400 & 0.89 \\
Stair upwards & 0.80 & 0.305 & 0.67 \\
\hline
\end{tabular}

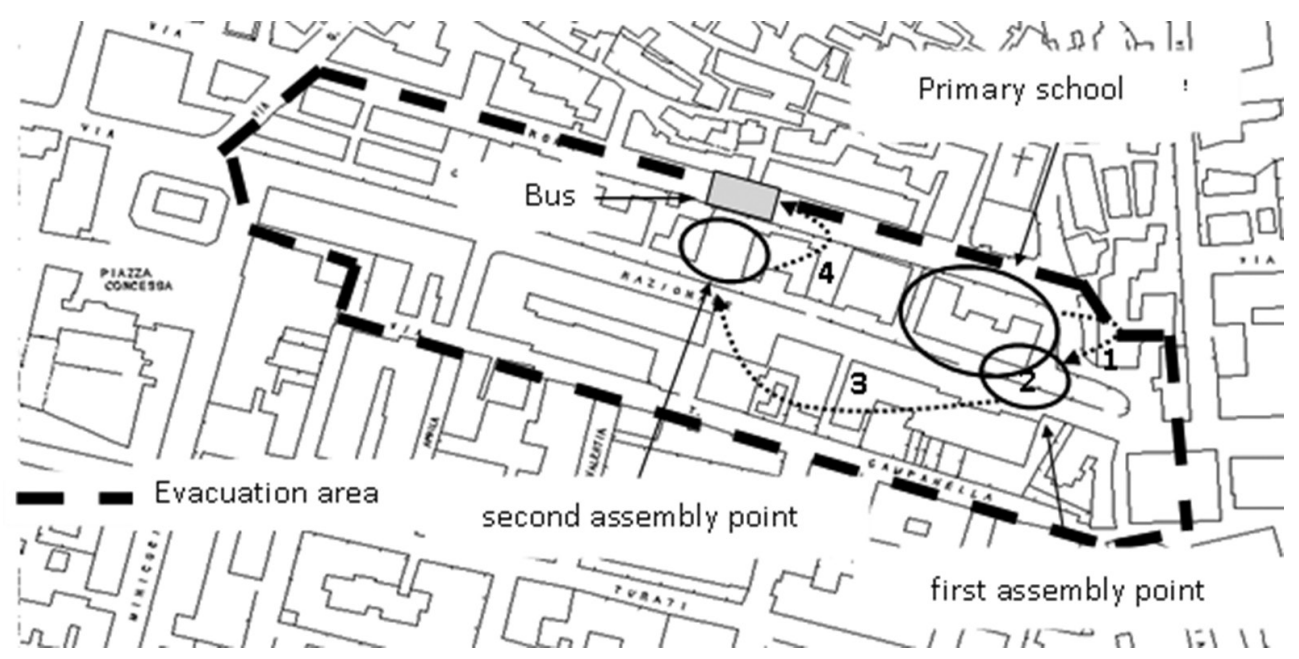

Figure 3: Phases of evacuation.

are involved. To compare the results of two drills, the measured evacuation times of school will be reported below.

Hence, evacuation of the school was schematized in the following five main phases: (1) evacuation of the building reaching first assembly point; (2) roll-call of pupils at first assembly point; 
(3) transfer to second assembly point; (4) boarding on bus and (5) transfer to refuge area. In the application here described, the analysis focuses on the evacuation of the first three phases.

Data were gathered concerning supply and demand. During the drill, a monitoring system was arranged, with manual/automatic tools and 12 video cameras, in order to acquire data concerning pedestrian outflow (times, densities) both inside and outside the building until the gathering places were reached.

\subsubsection{Mesoscopic simulation}

To validate the results of the methodology, a mesoscopic simulation has also been carried out. Simulation is realized applying a dynamic traffic assignment (DTA) model [57-60]. Applying this model, a simulation of the observed evacuation was performed. Evacuation routes were obtained from the school evacuation plan. As regards, the cost functions adopted, for fictitious links a constant speed function was considered; for corridors and descending flights, relationships between speed and specific flow specified and calibrated in [59] have been considered.

Demand values used in the simulation were obtained from school attendance on the experimentation day, and users were located in offices and classrooms following the real distribution. The demand value to be evacuated consists of about 150 users and evacuation routes were obtained directly from the school evacuation plan. The first three steps previously identified were simulated with a dynamic approach.

\subsubsection{Comparison of results}

Results obtained from the application of the above-described approaches have been expressed in terms of evacuation time. In Table 4, evacuation times for the evacuation of the building related to experimentation and to simulations are reported.

Some consideration can be made on the proposed approaches. For the mesoscopic simulation, the main advantage consists on the possibility to explicitly simulate queues and spill backs, whilst a drawback is given from the necessity to use a specific software. The proposed methodology gives an aggregate representation of flow conditions and does not allow a detailed analysis of them; on the other hand, it can be easily implemented on a spreadsheet.

\subsection{Application of the whole methodology}

The application of the whole methodology [61] was performed to define the evacuation routes on one of the provisional school units (MUSP - Lotto 16) built after L'Aquila earthquake of April 6, 2009. Plans of the two floors of the considered building are sketched in Fig. 4. The operations conducted at each step of the proposed procedure in the considered context are explained as follows.

Table 4: Comparison of evacuation time obtained from drill with simulated ones.

\begin{tabular}{lccc}
\hline Phase & $\begin{array}{c}\text { Measured } \\
\text { time }\end{array}$ & $\begin{array}{c}\text { Proposed } \\
\text { method }\end{array}$ & Mesosimulation \\
\hline $\begin{array}{l}\text { (1) Evacuation of building reaching first } \\
\text { assembly point }\end{array}$ & $4^{\prime} 14^{\prime \prime}$ & $4^{\prime} 23^{\prime \prime}$ & $5^{\prime} 47^{\prime \prime}$ \\
\hline
\end{tabular}



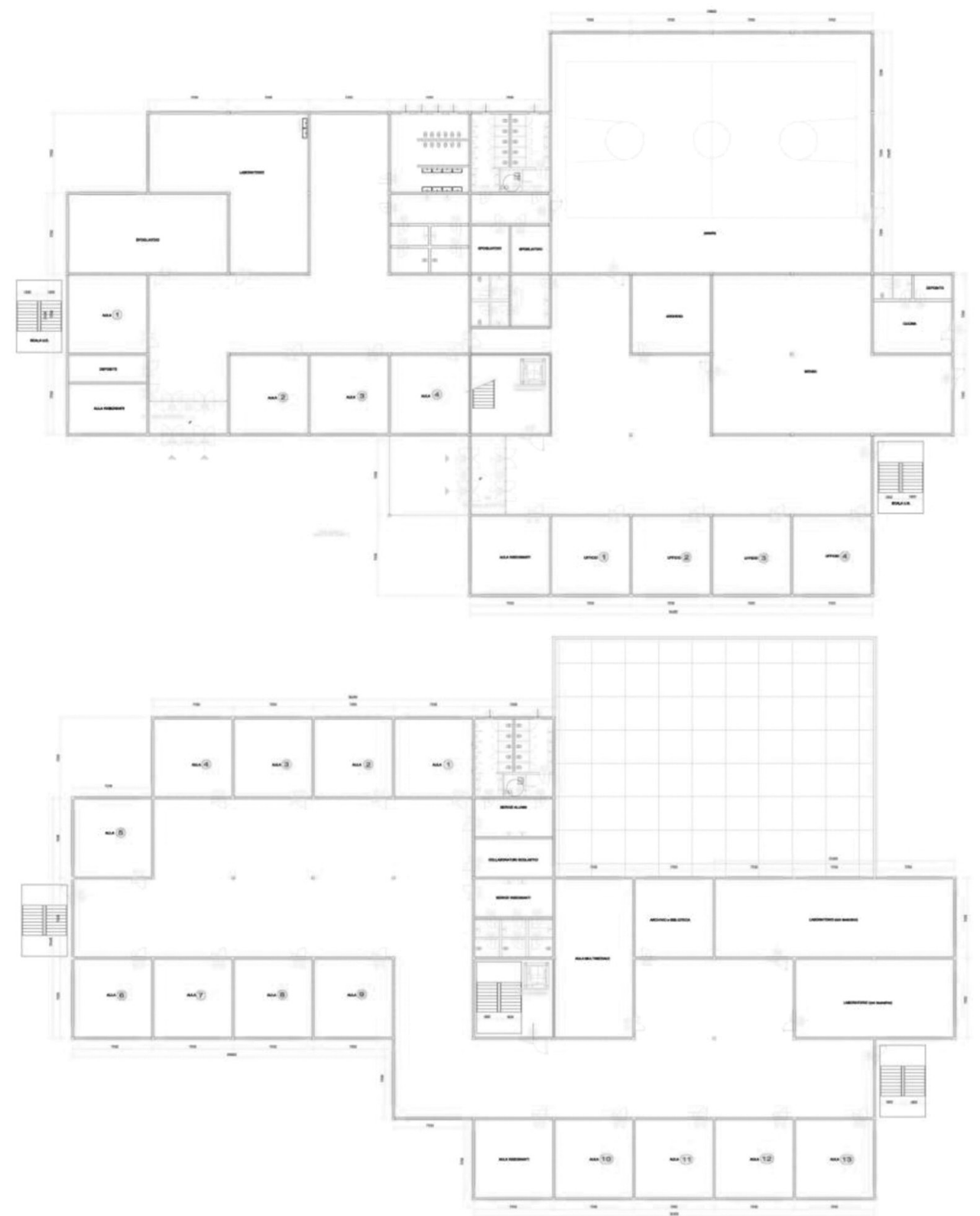

Figure 4: Plans of ground and first floor of the considered provisional school unit.

\subsection{Zoning of the building}

Considering each room as a distinct zone, 39 potential origins and 2 destinations outside the building have been identified. For the sake of simplicity, dressing rooms have not been considered as origin. Origins are treated as actual if, in the considered scenario, the presence of people attributed to the area they represent is thought. A centroid has been attributed to each zone. 
Table 5: Definition of occupants for each origin node.

\begin{tabular}{lrrrrrrrrrrrrrr}
\hline & \multicolumn{11}{c}{ Ground floor } \\
\hline Origin node & 1 & 3 & 4 & 5 & 6 & 11 & 12 & 13 & 14 & 15 & 16 & & \\
Occupants & 25 & 5 & 25 & 25 & 25 & 5 & 2 & 2 & 2 & 2 & 3 & & \\
\hline & 110 \\
\hline Origin node & 85 & 86 & 87 & 88 & 89 & 90 & 91 & 92 & 93 & 94 & 95 & 96 & 97 & 98 \\
Occupants & 25 & 25 & 25 & 25 & 25 & 25 & 25 & 25 & 25 & 5 & 25 & 25 & 25 & 25 \\
\hline
\end{tabular}

\subsection{Definition of the supply model}

The building has been schematized considering the network of all possible pathways. Corridors were considered in both directions and a specific arc has been considered for each door aperture. Resulting graph consists of 170 nodes and 189 arcs and is sketched in Fig. 5 (note that arcs related to vertical connections - stairs - are not visible).

\subsection{Definition of escape demand}

In the considered scenario, the hypothesis made is that only classrooms and offices are in use, no activities are conducted in laboratories and in the school gym, and there is no one in the toilets. Therefore, only 25 of the potential 39 origins are then considered, and occupants of each room correspondent to the origin node have been defined as indicated in Table 5 .

Following these hypotheses, the total number of occupants to evacuate is of 451 people, 330 located at the first floor and 121 located at the ground floor.

\subsection{Definition of escape routes}

Paths connecting the 25 origins with the two assembly point have been generated. To explore a wide range of alternatives, for each origin-destination, up to three evacuation route for each O/D pair have been taken into consideration. Free-flow time has been considered as cost of each arc; it is given by arc length divided by its free flow speed, supposed equal to $0.8 \mathrm{~m} / \mathrm{s}$ for corridors and $0.5 \mathrm{~m} / \mathrm{s}$ for descending stairs. A $k$-shortest path algorithm has been used to evaluate escape routes; results consist of 59 generated evacuation routes since, for some O/D pair, only one or two paths are obtainable. Obtained paths, described as sequence of nodes, are listed in Table 6 .

\subsection{Generation of evacuation configurations}

Considering the set of evacuation routes computed above, feasible evacuation scenarios have been built taking account of the selection rule consisting in eliminating those combinations where contra flow is potentially allowed.

Considering the compatibility incidence matrix $\boldsymbol{C}$ evaluated for the above-defined set of evacuation routes, starting from the 306110016 possible combinations obtained combining paths for all the $\mathrm{O} / \mathrm{D}$ pair each other, the application of the selection rule by means of the compatibility matrix reduces the number of feasible configuration to 22712. To enhance readability, matrix $C$ is summarized in Table 7 showing only the list of incompatible routes. 

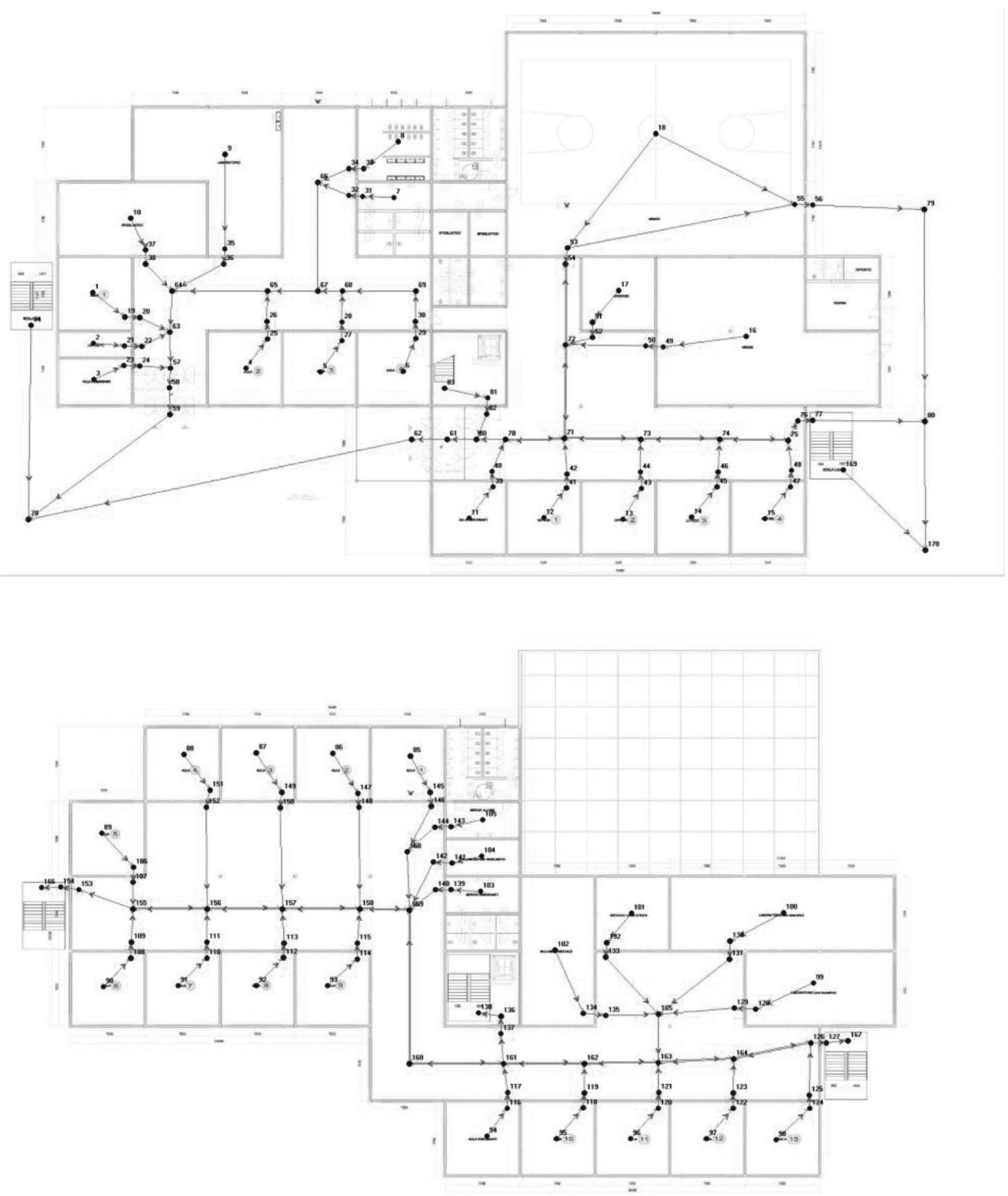

Figure 5: Graph of the pedestrian network of the considered provisional school unit.

3.8 Computation of flow variables and travel times and selection of scenario

For each one of the feasible configurations, using the aggregate model described before, travel times and flow characteristics are computed in order to define indicators on evacuation conditions. The effective scenario has been identified considering, among all the simulated configurations, the one that minimize evacuation time. The selection of a configuration implies the attribution of the safe area to be reached from evacuees; attribution of destinations (safe area) to each origin (room) is shown in Tab. 8. 
Table 6: Generated evacuation routes.

\begin{tabular}{|c|c|}
\hline Route & Nodes \\
\hline 1 & $1-19-20-63-57-58-59-78$ \\
\hline 2 & $3-23-24-57-58-59-78$ \\
\hline 3 & $4-25-26-65-64-63-57-58-59-78$ \\
\hline 4 & $5-27-28-68-67-65-64-63-57-58-59-78$ \\
\hline 5 & $6-29-30-69-68-67-65-64-63-57-58-59-78$ \\
\hline 6 & $11-39-40-70-60-61-62-78$ \\
\hline 7 & $11-39-40-70-71-73-74-75-76-77-80-170$ \\
\hline 8 & $12-41-42-71-70-60-61-62-78$ \\
\hline 9 & $12-41-42-71-73-74-75-76-77-80-170$ \\
\hline 10 & $13-43-44-73-71-70-60-61-62-78$ \\
\hline 11 & $13-43-44-73-74-75-76-77-80-170$ \\
\hline 12 & $14-45-46-74-73-71-70-60-61-62-78$ \\
\hline 13 & $14-45-46-74-75-76-77-80-170$ \\
\hline 14 & $15-47-48-75-74-73-71-70-60-61-62-78$ \\
\hline 15 & $15-47-48-75-76-77-80-170$ \\
\hline 16 & $16-49-50-72-71-70-60-61-62-78$ \\
\hline 17 & $16-49-50-72-71-73-74-75-76-77-80-170$ \\
\hline 18 & 85-145-146-168-159-158-157-156-155-153-154-166-84-78 \\
\hline 19 & $85-145-146-168-159-160-161-137-136-138-83-81-82-60-61-62-78$ \\
\hline 20 & 85-145-146-168-159-160-161-162-163-164-126-127-167-169-170 \\
\hline 21 & $86-147-148-158-157-156-155-153-154-166-84-78$ \\
\hline 22 & $86-147-148-158-159-160-161-137-136-138-83-81-82-60-61-62-78$ \\
\hline 23 & $86-147-148-158-159-160-161-162-163-164-126-127-167-169-170$ \\
\hline 24 & $87-149-150-157-156-155-153-154-166-84-78$ \\
\hline 25 & 87-149-150-157-158-159-160-161-137-136-138-83-81-82-60-61-62-78 \\
\hline 26 & $87-149-150-157-158-159-160-161-162-163-164-126-127-167-169-170$ \\
\hline 27 & $88-151-152-156-155-153-154-166-84-78$ \\
\hline 28 & 88-151-152-156-157-158-159-160-161-137-136-138-83-81-82-60-61-62-78 \\
\hline 29 & 88-151-152-156-157-158-159-160-161-162-163-164-126-127-167-169-170 \\
\hline 30 & $89-106-107-155-153-154-166-84-78$ \\
\hline 31 & 89-106-107-155-156-157-158-159-160-161-137-136-138-83-81-82-60-61-62-78 \\
\hline 32 & 89-106-107-155-156-157-158-159-160-161-162-163-164-126-127-167-169-170 \\
\hline 33 & $90-108-109-155-153-154-166-84-78$ \\
\hline 34 & 90-108-109-155-156-157-158-159-160-161-137-136-138-83-81-82-60-61-62-78 \\
\hline 35 & $90-108-109-155-156-157-158-159-160-161-162-163-164-126-127-167-169-170$ \\
\hline 36 & $91-110-111-156-155-153-154-166-84-78$ \\
\hline 37 & 91-110-111-156-157-158-159-160-161-137-136-138-83-81-82-60-61-62-78 \\
\hline 38 & 91-110-111-156-157-158-159-160-161-162-163-164-126-127-167-169-170 \\
\hline 39 & $92-112-113-157-156-155-153-154-166-84-78$ \\
\hline 40 & 92-112-113-157-158-159-160-161-137-136-138-83-81-82-60-61-62-78 \\
\hline
\end{tabular}


Table 6: Continued

\begin{tabular}{ll}
\hline Route & \multicolumn{1}{c}{ Nodes } \\
\hline 41 & $92-112-113-157-158-159-160-161-162-163-164-126-127-167-169-170$ \\
42 & $93-114-115-158-157-156-155-153-154-166-84-78$ \\
43 & $93-114-115-158-159-160-161-137-136-138-83-81-82-60-61-62-78$ \\
44 & $93-114-115-158-159-160-161-162-163-164-126-127-167-169-170$ \\
45 & $94-116-117-161-137-136-138-83-81-82-60-61-62-78$ \\
46 & $94-116-117-161-160-159-158-157-156-155-153-154-166-84-78$ \\
47 & $94-116-117-161-162-163-164-126-127-167-169-170$ \\
48 & $95-118-119-162-161-137-136-138-83-81-82-60-61-62-78$ \\
49 & $95-118-119-162-161-160-159-158-157-156-155-153-154-166-84-78$ \\
50 & $95-118-119-162-163-164-126-127-167-169-170$ \\
51 & $96-120-121-163-162-161-137-136-138-83-81-82-60-61-62-78$ \\
52 & $96-120-121-163-162-161-160-159-158-157-156-155-153-154-166-84-78$ \\
53 & $96-120-121-163-164-126-127-167-169-170$ \\
54 & $97-122-123-164-163-162-161-137-136-138-83-81-82-60-61-62-78-$ \\
55 & $97-122-123-164-163-162-161-160-159-158-157-156-155-153-154-166-84-78$ \\
56 & $97-122-123-164-126-127-167-169-170$ \\
57 & $98-124-125-126-164-163-162-161-137-136-138-83-81-82-60-61-62-78$ \\
58 & $98-124-125-126-164-163-162-161-160-159-158-157-156-155-153-154-166-84-78$ \\
59 & $98-124-125-126-127-167-169-170$ \\
\hline
\end{tabular}

Table 7: List of incompatible routes obtained by compatibility incidence matrix $C$.

\begin{tabular}{ll}
\hline Route & \\
\hline 7 & $8-10-12-14-16$ \\
8 & 7 \\
9 & $10-12-14$ \\
10 & $7-9-17$ \\
11 & $12-14$ \\
12 & $7-9-11-17$ \\
13 & 14 \\
14 & $7-9-11-13-17$ \\
16 & 7 \\
17 & $10-12-14$ \\
18 & $22-23-25-26-28-29-31-32-34-35-37-38-40-41-43-44$ \\
19 & $46-49-52-55-58$ \\
20 & $46-48-49-51-52-54-55-57-58$ \\
21 & $25-26-28-29-31-32-34-35-37-38-40-41$ \\
22 & $18-46-49-52-55-58$ \\
23 & $18-46-48-49-51-52-54-55-57-58$ \\
24 & $28-29-31-32-34-35-37-38$
\end{tabular}


Table 7: Continued

\begin{tabular}{|c|c|}
\hline Route & Incompatible routes \\
\hline 25 & $18-21-42-46-49-52-55-58$ \\
\hline 26 & $18-21-42-46-48-49-51-52-54-55-57-58$ \\
\hline 27 & $31-32-34-35$ \\
\hline 28 & $18-21-24-39-42-46-49-52-55-58$ \\
\hline 29 & $18-21-24-39-42-46-48-49-51-52-54-55-57-58$ \\
\hline 31 & $18-21-24-27-36-39-42-46-49-52-55-58$ \\
\hline 32 & $18-21-24-27-36-39-42-46-48-49-51-52-54-55-57-58$ \\
\hline 34 & $18-21-24-27-36-39-42-46-49-52-55-58$ \\
\hline 35 & $18-21-24-27-36-39-42-46-48-49-51-52-54-55-57-58$ \\
\hline 36 & $31-32-34-35$ \\
\hline 37 & $18-21-24-39-42-46-49-52-55-58$ \\
\hline 38 & $18-21-24-39-42-46-48-49-51-52-54-55-57-58$ \\
\hline 39 & $28-29-31-32-34-35-37-38$ \\
\hline 40 & $18-21-42-46-49-52-55-58$ \\
\hline 41 & $18-21-42-46-48-49-51-52-54-55-57-58$ \\
\hline 42 & $25-26-28-29-31-32-34-35-37-38-40-41$ \\
\hline 43 & $18-46-49-52-55-58$ \\
\hline 44 & $18-46-48-49-51-52-54-55-57-58$ \\
\hline 46 & $19-20-22-23-25-26-28-29-31-32-34-35-37-38-40-41-43-44$ \\
\hline 47 & $48-49-51-52-54-55-57-58$ \\
\hline 48 & $20-23-26-29-32-35-38-41-44-47$ \\
\hline 49 & $19-20-22-23-25-26-28-29-31-32-34-35-37-38-40-41-43-44-47$ \\
\hline 50 & $51-52-54-55-57-58$ \\
\hline 51 & $20-23-26-29-32-35-38-41-44-47-50$ \\
\hline 52 & $19-20-22-23-25-26-28-29-31-32-34-35-37-38-40-41-43-44-47-50$ \\
\hline 53 & $54-55-57-58$ \\
\hline 54 & $20-23-26-29-32-35-38-41-44-47-50-53$ \\
\hline 55 & $19-20-22-23-25-26-28-29-31-32-34-35-37-38-40-41-43-44-47-50-53$ \\
\hline 56 & $57-58$ \\
\hline 57 & $20-23-26-29-32-35-38-41-44-47-50-53-56$ \\
\hline 58 & $19-20-22-23-25-26-28-29-31-32-34-35-37-38-40-41-43-44-47-50-53-56$ \\
\hline
\end{tabular}

Table 8: Definition of safe area for each origin node.

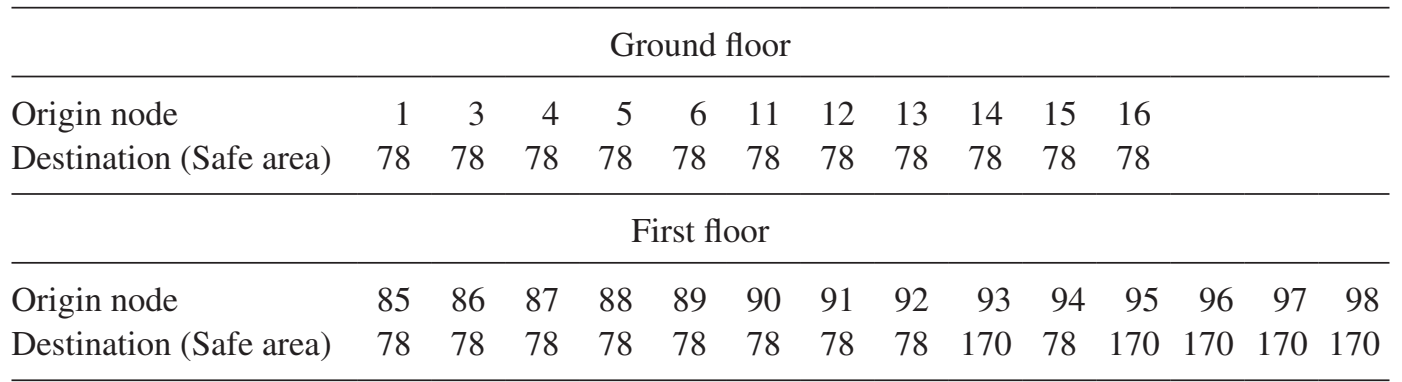


Results obtained for optimal configuration, for each O/D pair, are shown in Tab 9, in terms of escape routes, and in Tab 10, in terms of travel times.

In Table 11, some statistics expressed in terms of evacuation time and total time are shown, whilst indicators obtained for the selected configuration are summarized in Table 12.

\subsection{Computational issues}

Since one of the aims of this work was to build up a simple tools able to quantify, in terms of evacuation time, the effectiveness of an evacuation plan, the whole procedure, except for the zoning and the graph definition, has been implemented in a Microsoft Excel spreadsheet where the modules of the procedure were coded using the VBA language.

Running times for each step, obtained on an AMD Athlon II, 2 GB RAM with Windows 7 OS and Office 2007, are shown in Table 13.

Table 9: List of escape routes for each O/D pair for optimal configuration.

\begin{tabular}{ll}
\hline O/D pairs & \multicolumn{1}{c}{ Nodes } \\
\hline 1 & $1-19-20-63-57-58-59-78$ \\
2 & $3-23-24-57-58-59-78$ \\
3 & $4-25-26-65-64-63-57-58-59-78$ \\
4 & $5-27-28-68-67-65-64-63-57-58-59-78$ \\
5 & $6-29-30-69-68-67-65-64-63-57-58-59-78$ \\
6 & $11-39-40-70-60-61-62-78$ \\
7 & $12-41-42-71-70-60-61-62-78$ \\
8 & $13-43-44-73-71-70-60-61-62-78$ \\
9 & $14-45-46-74-73-71-70-60-61-62-78$ \\
10 & $15-47-48-75-74-73-71-70-60-61-62-78$ \\
11 & $16-49-50-72-71-70-60-61-62-78$ \\
12 & $85-145-146-168-159-160-161-137-136-138-83-81-82-60-61-62-78$ \\
13 & $86-147-148-158-159-160-161-137-136-138-83-81-82-60-61-62-78$ \\
14 & $87-149-150-157-156-155-153-154-166-84-78$ \\
15 & $88-151-152-156-155-153-154-166-84-78$ \\
16 & $99-106-107-155-153-154-166-84-78$ \\
17 & $91-1108-109-155-153-154-166-84-78$ \\
18 & $92-112-113-156-155-153-154-166-84-78$ \\
19 & $93-114-115-158-159-160-161-162-163-164-126-127-167-169-170$ \\
20 & $94-116-117-161-137-136-138-83-81-82-60-61-62-78$ \\
21 & $95-118-119-162-163-164-126-127-167-169-170$ \\
22 & $96-120-121-163-164-126-127-167-169-170$ \\
23 & $97-122-123-164-126-127-167-169-170$ \\
24 & $98-124-125-126-127-167-169-170$ \\
25 &
\end{tabular}


Table 10: Travel times for each O/D pair for optimal configuration.

\begin{tabular}{lccccr}
\hline Path & Origin & Destination & Running time & Queue time & Total time \\
\hline 1 & 1 & 78 & 82.73 & 81.10 & 4095.90 \\
2 & 3 & 78 & 40.52 & 54.37 & 474.42 \\
3 & 4 & 78 & 99.18 & 95.13 & 4857.74 \\
4 & 5 & 78 & 112.22 & 103.81 & 5400.95 \\
5 & 6 & 78 & 120.52 & 105.49 & 5650.19 \\
6 & 11 & 78 & 78.45 & 37.42 & 579.35 \\
7 & 12 & 78 & 82.33 & 35.11 & 234.89 \\
8 & 13 & 78 & 88.22 & 35.11 & 246.67 \\
9 & 14 & 78 & 94.79 & 35.11 & 259.82 \\
10 & 15 & 78 & 100.60 & 35.11 & 271.43 \\
11 & 16 & 78 & 97.66 & 35.88 & 400.62 \\
12 & 85 & 78 & 215.82 & 216.74 & 10813.85 \\
13 & 86 & 78 & 226.94 & 216.74 & 11091.83 \\
14 & 87 & 78 & 159.32 & 279.16 & 10962.12 \\
15 & 88 & 78 & 145.73 & 277.49 & 10580.42 \\
16 & 89 & 78 & 125.94 & 273.15 & 9977.10 \\
17 & 90 & 78 & 120.83 & 273.15 & 9849.48 \\
18 & 91 & 78 & 131.88 & 277.49 & 10234.15 \\
19 & 92 & 78 & 141.62 & 279.16 & 10519.58 \\
20 & 93 & 170 & 189.64 & 256.16 & 11144.89 \\
21 & 94 & 78 & 129.97 & 183.99 & 1569.76 \\
22 & 95 & 170 & 135.71 & 238.79 & 9362.57 \\
23 & 96 & 170 & 125.26 & 234.45 & 8992.83 \\
24 & 97 & 170 & 114.52 & 227.44 & 8548.85 \\
25 & 98 & 170 & 110.56 & 217.75 & 8207.88 \\
\hline
\end{tabular}

Table 11: Statistics obtained for the whole set of configurations.

\begin{tabular}{|c|c|c|c|c|c|c|}
\hline & \multicolumn{2}{|c|}{ Min } & \multicolumn{2}{|c|}{ Max } & \multirow[b]{2}{*}{ Mean (s) } & \multirow[b]{2}{*}{ Var. $\left(s^{2}\right)$} \\
\hline & Time (s) & Scenario & Time (s) & Scenario & & \\
\hline Evacuation time & 445 & 90 & 1432 & 232 & 744 & 9275 \\
\hline Total time & 153024 & 19963 & 480711 & 232 & 216296 & 7.77E+08 \\
\hline
\end{tabular}

Table 12: Indicators obtained for optimal configuration.

\begin{tabular}{lcc}
\hline Indicator & Time (s) & Time (hh:mm:ss) \\
\hline Evacuation time & 445 & $00: 07: 25$ \\
Total time & 154327 & $42: 52: 07$ \\
Max queue time & 279 & $00: 04: 39$ \\
Total queue time & 93097 & $25: 51: 37$ \\
\hline
\end{tabular}


Table 13: Running time for each step of the procedure.

\begin{tabular}{lc}
\hline Step & Time (s) \\
\hline Path generation & 0.406 \\
Evaluation of path compatibility & 3.543 \\
Generation of alternatives & 1.328 \\
Evaluation of alternatives & 40.387 \\
\hline
\end{tabular}

\section{CONCLUSIONS AND PERSPECTIVES}

The main result of this paper concerns a method for the definition of effective escape routes by means of the simulation of pedestrian outflow related to the evacuation of a building using an aggregate model for the estimation of evacuation time.

Simulating evacuation by means of more sophisticated approaches on the one hand, can make more effective the selection of effective evacuation routes while on the other hand requires the availability of specific software.

Such a method can be easily implemented in a worksheet and can be used to give a first evaluation of evacuation procedures without performing evacuation drills and so can be used to give a fast response in identifying critical points on the network.

A comparison between experimental data and simulation results shows how the usage of appropriate simulation models can realistically reproduce user behavior. The capabilities of the proposed approach have been shown by means of an application on a real case.

Implementation of appropriate cost functions can make the applied methodologies suitable for any building and/or area with homogeneous characteristics in terms of activities. Further investigations on travel time functions under different operative conditions are in progress. An extension of the method introducing a simplified dynamic assignment model is also under development.

\section{ACKNOWLEDGMENTS}

The author thanks Prof. Mauro Dolce and Dr. Elvezio Galanti, members of the Italian Civil Protection, for their support in the availability of details on the provisional school unit of L'Aquila considered in the application.

\section{REFERENCES}

[1] Russo, F. \& Vitetta, A., Risk evaluation in a transportation system. International Journal of Sustainable Development and Planning, 1 (2), pp. 170-191, 2006. doi: http://dx.doi.org/ 10.2495/sdp-v1-n2-170-191

[2] Di Gangi, M. \& Velonà, P., Deflusso pedonale negli edifici in condizioni di emergenza-modelli e metodi per la simulazione, applicazione ad un caso reale. Franco Angeli: Milano, ISBN $9788846490650,2007$.

[3] Russo, F. \& Chilà G., Safety of users in road evacuation: demand model. Urban Transport XIII, ed. C.A. Brebbia WIT Press, pp. 773-782 ISBN 9781845640873, 2007.

[4] Russo, F. \& Chilà G., A sequential dynamic choice model to simulate demand in evacuation conditions. Proc. of Risk analysis VII \& Brownfields V, ed. C.A. Brebbia, WIT Press: Southampton, pp. 431-442, 2010.

[5] Russo, F. \& Rindone, C., Evaluation methods for evacuation planning. Proc. of Urban Transport XVI, Urban Transport and the Environment in the 21 st century, ed. C.A. Brebbia, WIT Press: Southampton, pp. 335-343, 2010. 
[6] Gwynne, S., Galea, E.R., Lawrence, P.J., Owen, M. \& Filippidis, L., A review of the methodologies used in the computer simulation of evacuation from the built environment. Building and Environment, 34, pp. 741-749, 1999. doi: http://dx.doi.org/10.1016/s0360-1323(98)00057-2

[7] Fire Model Survey, International Survey of Computer Models for Fire and Smoke [online], available at http://www.firemodelsurvey.com/EgressModels.html (accessed 2007).

[8] Kuligowski, E.D. \& Peacock, R.D. A Review of Building Evacuation Models. Technical note no. 1471. National Institute of Standards and Technology, Gaithesburgh, MD, 2005.

[9] Olenick, S.M. \& Carpenter, D.J., An updated international survey of computer models for fire and smoke. Journal of Fire Protection Engineering, 13, pp. 87-110, 2003. doi: http://dx.doi. org/10.1177/1042391503013002001

[10] Burstedde, C., Klauck, K., Schadschneider, A. \& Zittartz, J., Simulation of pedestrian dynamics using a two-dimensional cellular automaton. Physica A, 295, pp. 507-525, 2001. doi: http:// dx.doi.org/10.1016/s0378-4371(01)00141-8

[11] Yuan, W. \& Tan, K.H., A novel algorithm of simulating multi-velocity evacuation based on cellular automata modeling and tenability condition. Physica A, 379, pp. 250-262, 2007. doi: http://dx.doi.org/10.1016/j.physa.2006.12.044

[12] Varas, A., Cornejo, M.D., et al., Cellular automaton model for evacuation process with obstacles. Physica A, 382, pp. 631-642, 2007. doi: http://dx.doi.org/10.1016/j.physa.2007.04.006

[13] Weng, W.G., Chen, T., Yuan, H.Y. \& Fan, W.C., Cellular automaton simulation of pedestrian counter flow with different walk velocities. Physical Review E, 74, 036102, 2006. doi: http:// dx.doi.org/10.1103/physreve.74.036102

[14] Yang, L.Z., Zhao, D.L., Li, J. \& Fang, T.Y., Simulation of the kin behavior in building occupant evacuation based on cellular automaton. Building and Environment, 40, pp. 411-415, 2005. doi: http://dx.doi.org/10.1016/j.buildenv.2004.08.005

[15] Zhao, D.L., Yang, L.Z. \& Li, J., Occupants' behavior of going with the crowd based on cellular automata occupant evacuation model. Physica A, 387, pp. 3708-3718, 2008. doi: http://dx.doi. org/10.1016/j.physa.2008.02.042

[16] Kirchner, A., Nishinari, K. \& Schadschneider, A., Friction effects and clogging in a cellular automaton model for pedestrian dynamics. Physical Review E, 67, 056122, 2003. doi: http:// dx.doi.org/10.1103/physreve.67.056122

[17] Henein, C.M. \& White, T., Macroscopic effects of microscopic forces between agents in crowd models. Physica A, 373, pp. 694-712, 2007. doi: http://dx.doi.org/10.1016/j.physa.2006.06.023

[18] Tajima, Y., Takimoto, K. \& Nagatani, T., Pattern formation and jamming transition in pedestrian counter flow. Physica A, 313, pp. 709-723, 2002. doi: http://dx.doi.org/10.1016/s03784371(02)00965-2

[19] Helbing, D., Isobe, M., Nagatani, T. \& Takimoto, K., Lattice gas simulation of experimentally studied evacuation dynamics. Physical Review E, 67, 067101, 2003. doi: http://dx.doi. org/10.1103/physreve.67.067101

[20] Isobe, M., Adachi, T. \& Nagatani, T., Experiment and simulation of pedestrian counter flow. Physica A, 336, 638-650, 2004. doi: http://dx.doi.org/10.1016/j.physa.2004.01.043

[21] Nagai, R., Nagatani, T., Isobe, M. \& Adachi, T., Effect of exit configuration on evacuation of a room without visibility. Physica A, 343, 712-724, 2004. doi: http://dx.doi.org/10.1016/s0378-4371(04)00851-9

[22] Zhang, J., Song, W. \& Xu, X., Experiment and multi-grid modeling of evacuation from a classroom. Physica A, 387, 5901-5909, 2008. doi: http://dx.doi.org/10.1016/j.physa.2008.06.030

[23] Nagatani, T., Dynamical transition and scaling in a mean-field model of pedestrian flow at a bottleneck. Physica A, 300, 558-566, 2001. doi: http://dx.doi.org/10.1016/s0378-4371(01)00366-1

[24] Helbing, D. \& Molnár, P., Social force model for pedestrian dynamics. Physical Review E, 51, 4282-4286, 1995. doi: http://dx.doi.org/10.1103/physreve.51.4282 
[25] Kirchner, A. \& Schadschneider, A., Simulation of evacuation processes using a bionics-inspired cellular automaton model for pedestrian dynamics. Physica A, 312, 260-276, 2002. doi: http://dx.doi.org/10.1016/s0378-4371(02)00857-9

[26] Helbing, D., Farkas, I.J., Molnár, P. \& Vicsek, T., Simulation of pedestrian crowds in normal and evacuation situations. Pedestrian and Evacuation Dynamics, eds. M. Schreckenberg and S.D. Sharma, Springer, pp. 21-58, 2002.

[27] Yang, L.Z., Fang, W.F. \& Fan, W.C., Modeling occupant evacuation using cellular automata effect of human behavior and building characteristics on evacuation. Journal of Fire Science, 21, 227-240, 2003. doi: http://dx.doi.org/10.1177/0734904103021003004

[28] Zhao, D.L., Yang, L.Z., Li, J., Zhu, Y. \& Zou, L., Relationship between performancebased design of building exits and state transition of pedestrian flow during occupant evacuation. Journal of Fire Protection Engineering, 16, 269-281, 2006. doi: http://dx.doi. org/10.1177/1042391506061523

[29] ASERI (Advance Simulation of Evacuation of Real Individuals). A model to simulate evacuation and egress movement based on individual behavioural response, available at http://www.ist-net.de, 2004.

[30] Gwynne, S., Galea, E.R., Lawrence, P. \& Filippidis, L., A systematic comparison of model predictions produced by the building EXODUS evacuation model and the Tsukuba Pavilion evacuation data. Applied Fire Science, 7, pp. 235-266, 1998. doi: http://dx.doi. org/10.2190/6w20-vm9d-y3f2-qghe

[31] Parke, J., Gwynne, S., Galea, E.R. \& Lawrence, P., Validating the building EXODUS evacuation model using data from an unannounced trial evacuation. Proceedings of 2 nd International Pedestrian and Evacuation Dynamics Conference, ed. E.R. Galea, CMS Press; Greenwich, UK ISBN 1904521088, pp. 295-306, 2003.

[32] Fraser-Mitchell, J., Simulated evacuations of an airport terminal building, using the CRISP model. 2nd International Symposium in Human Behaviour in Fire, Boston, MA, pp. 89-100. 2001.

[33] Ketchell, N., Cole, S.S. \& Webber, D.M., The EGRESS code for human movement and behaviour in emergency evacuation. Engineering for Crowd Safety, eds R.A. Smith \& J.F. Dickie, Elsevier: London, pp. 361-370. 1994.

[34] Francis, R.L. \& Saunders, P.B., EVACNET: Prototype Network Optimization Models for Building Evacuation (Rep. No. NBSIR 79-1593). Natational Bureau Standards (U.S.), 1979.

[35] Fahy, R.F., EXIT89 - an evacuation model for high-rise buildings - model description and example applications. Fire Safety Science - Proceedings of the 4th International Symposium, pp. 657-668, 1994. doi: http://dx.doi.org/10.3801/iafss.fss.4-657

[36] Levin, B.M., EXITT - a simulation model of occupant decisions and actions in residential fires. Fire Safety Science - Proceedings of the Second International Symposium, pp. 561-570, 1988. doi: http://dx.doi.org/10.3801/iafss.fss.2-561

[37] Bensilum, M. \& Purser, D.A., Gridflow: an object-oriented building evacuation model combining pre-movement and movement behaviours for performance-based design. 7th International Symposium on Fire Safety Science Worcester, Worcester Polytechnic Institute: MA, 2002.

[38] Berrou, J.L., Beecham, J., Quaglia, P., Kagarlis, M.A. \& Gerodimos, A., Calibration and validation of the Legion simulation model using empirical data, Available at http://www. legion.com/about-us/Publications.php, 2005.

[39] Cappuccio, J., Pathfinder: a computer-based timed egress simulation. Fire Protection Engineering, 8, pp. 11-12, 2000.

[40] Klupfel, H. \& Meyer-König, T., Characteristics of the PedGo software for crowd movement and egress simulation. . Proceedings of 2nd International Pedestrian and Evacuation Dynamics Conference, ed. E.R. Galea, CMS Press, Greenwich, UK, ISBN 1904521088, pp. 331-340, 2003. 
[41] Meyer-König, T., Klupfel, H. \& Schreckenberg, M., A microscopic model for simulating mustering and evacuation process onboard passenger ships. Proceedings of the International Emergency Management Society Conference, 2001. doi: http://dx.doi.org/10.1007/978-1-4471-0709-5_8

[42] Buckmann, L.T. \& Leather, J., Modelling station congestion the PEDROUTE way. Traffic Engineering and Control, 35, pp. 373-377, 1994.

[43] Barton, J. \& Leather, J., Paxport - passenger and crowd simulation. Passenger Terminal '95, pp. 71-77, 1995.

[44] Di Gangi, M., Russo, F. \& Vitetta, A., A mesoscopic method for evacuation simulation on passenger ships: models and algorithms. Pedestrian and Evacuation Dynamics 2003, CMS Press: London, ISBN 1-904521-08-8, pp. 197-208, 2003.

[45] Oven, V.A. \& Cakici, N., Modelling the evacuation of a high-rise office building in Istanbul. Fire Safety Journal, 44, pp. 1-15, 2009. doi: http://dx.doi.org/10.1016/j.firesaf.2008.02.005

[46] Proulx, G., Evacuation time and movement in apartment buildings. Fire Safety Journal, 24(3), 1995, pp. 229-246. doi: http://dx.doi.org/10.1016/0379-7112(95)00023-m

[47] Smith, R.A., Density, velocity and flow relationships for closely packed crowds. Safety Science, 18(4), 1995, pp. 321-327. doi: http://dx.doi.org/10.1016/0925-7535(94)00051-4

[48] Fang, Z., Lob, S.M. \& Luc, J.A., On the relationship between crowd density and movement velocity. Fire Safety Journal, 18(3), pp. 271-283, 2003

[49] Kholshevnikov, V.V., Shields T.J., Boyce, K.E. \& Samoshin, D.A., Recent developments in pedestrian flow theory and research in Russia. Fire Safety Journal, 43, pp. 108-118, 2008. doi: http://dx.doi.org/10.1016/j.firesaf.2007.05.005

[50] Hughes, R.L., A continuum theory for the flow of pedestrians. Transportation Research Part B, 36, pp. 507-535, 2002. doi: http://dx.doi.org/10.1016/s0191-2615(01)00015-7

[51] Huang, L., Wong, S.C., Zhang, M., Shu, C. \& Lam, W.H.K., Revisiting Hughes' dynamic continuum model for pedestrian flow and the development of an efficient solution algorithm. Transportation Research Part B, 43(1), pp. 127-141, 2009. doi: http://dx.doi.org/10.1016/j.trb.2008.06.003

[52] Yen, J.Y., The k shortest loopless paths in a network. Management Science, 17(11), pp. $712-$ 716, 1971. doi: http://dx.doi.org/10.1287/mnsc.17.11.712

[53] Gallo G. \& Pallottino, S., Shortest path algorithms. Annals of Operational Research, 13, pp. 3-79, 1988. doi: http://dx.doi.org/10.1007/bf02288320

[54] Eppstein, D., Bibliography on algorithms for k shortest paths, available at: http://liinwww.ira. uka.de/bibliography/Theory/k-path.html, updated until 2001.

[55] Di Gangi, M., Evaluation of reliable path in risk areas. Risk Analysis V, WIT Press: Southampton, UK, pp. 371-377, 2006.

[56] Di Gangi, M., Musolino, G., Rindone, C. \& Vitetta, A., An Italian project for exposure reduction in an urban area: experimentation design and DSS development. Proceedings of European Transport Conference, Strasbourg, September 2006, ISBN/ISSN: 1-905701-01-2, 2006.

[57] Di Gangi, M., Approaching the analysis of transport networks in emergency conditions for the design of evacuation plans. Risk Analysis IV, WIT Press. ISBN 1-85312-736-1, pp. 485-494, 2006.

[58] Di Gangi, M., Planning evacuation by means of a multi-modal mesoscopic dynamic traffic simulation model., Geocomputation \& Urban Planning, SCI 176, eds. B. Murgante, G. Borruso \& A. Lapucci, Springer-Verlag: Berlin, Heidelberg, ISBN: 978-3-540-89929-7, pp. 99-115, 2009.

[59] Di Gangi, M. \& Velonà, P., Multimodal mesoscopic approach in modelling pedestrian evacuation. Transportation Research Record, 2090, 2009; pp. 51-58. ISSN: 0361-1981, doi: 10.3141/2090-06.

[60] Di Gangi, M., Modeling evacuation of a transport system: application of a multimodal mesoscopic dynamic traffic assignment model. IEEE Transactions on Intelligent Transportation Systems, 12(4), pp. 1157-1166, 2011. doi: 10.1109/TITS.2011.2143408.

[61] Di Gangi, M., Designing escape routes for buildings through an aggregate approach, WIT Transactions on Ecology and the Environment, 173, pp. 791-802 doi: 10.2495/SDP130661. 